\title{
Nuclear Latency: The Turkish Case
}

\author{
Hakan Mehmetcik
}

\begin{abstract}
Turkey's interest in nuclear technology has increased over the years. The aim of this article is to summarize, synthetize, update, and contextualize Turkey's nonproliferation policies and link it to the broader discussion on nuclear latency. The article first attempts to show the shortcomings of several latency arguments by overviewing the factors that affect Turkey's latency status. The main finding of the article is that Turkey's latency in terms of technology will increase, yet that increase cannot be predicted as potent enough to result in latency potential in terms of a nuclear weapons program in the short- and medium-term without a serious change in international and domestic politics.
\end{abstract}

Keywords nuclear latency, non-proliferation, proliferation, Turkey, Turkish nuclear diplomacy

\section{Introduction}

The central subject of this article is the latency issue with regard to the Turkish case. Turkey is often listed as a highly possible proliferator within the community of nuclear experts (Varnum 2010). Parallel to this, there are numerous studies predicting how and under which conditions Turkey may pursue nuclear weapons (ibid.; Güney 2012; Ulgen 2012; Stein 2015). Yet, almost no one has focused on the issue of latency in the Turkish context despite growing interest in the nuclear related technology of the country.

States access to technology, materials, and expertise have increased over the previous decades thanks to technology and scientific diffusion and globalization (Pilat 2015). "What was once exotic is now pedestrian, and nuclear weapons are no exception" (Kemp 2014). Therefore, proliferation of nuclear related technology is now one of several stresses for the non-proliferation regime. The concern of latent proliferation capability is far larger than actual nuclear proliferation even though there is much less attention to this issue in the literature. Latency is generally associated with indigenous and industrial scale civilian nuclear 
technology (Bunn 2001; Bluth et al. 2010; Yim and Li 2013). Indeed, the line between horizontal and latent proliferation is sometimes difficult to draw because all steps of a civilian nuclear energy industry are somehow identical with a military nuclear weapon program. Yet, the borderline between civilian and military use of nuclear energy clearly exists and case-by-case analyses taking into account of the nature of the nuclear program and motivations need to be made. After all, the existing studies show an insignificant correlation between the spread of the civilian use of the nuclear technology and actual nuclear weapon proliferation (Miller 2017).

As a matter of fact, it is very unlikely that Turkey would voluntarily damage its clean proliferation record and its relations with the rest of the world by pursuing an opaque/open/secret nuclear weapon program. Yet, latency, as a means of technological hedging against future security risks, could be a path Turkey would (if it ever does) prefer and Turkish nuclear diplomacy implies a latency preference. This article has employed a descriptive analysis based on open source materials to tackle the Turkish case by asking three important questions: how latent is Turkey? How latent could Turkey be in the short- and long-term? And what are the latency motivations for Turkey? First, a discussion on the issue of latency and some difficulties in the definition is provided. Then the article addresses Turkish latency in the short- and long-term by analyzing Turkish nuclear ambitions, and lastly tackles Turkish latency motivations.

\section{Nuclear Latency Hazard: Defining a Latent Nuclear Power}

Theoretically, states follow four strategies of nuclear pursuit: hedging, sprinting, hiding, and sheltering (Narang 2017). Latency is not one of them, yet it is an integral part of almost every strategy. Hedging is the closest variant as it is difficult to demarcate hedging and latency on both theoretical and empirical grounds. Hedging generally involves work on nuclear explosives, fissile materials, weapon designs, delivery systems, as well as bureaucratic capacities to manage nuclear capabilities, while nuclear latency generally refers to virtual proliferation as having weapon-grade nuclear material and technology in a civilian nuclear program without having made the decision to actually assemble and deploy a bomb (Mazarr 1997; Pilat 1997). That is, a latent proliferator stays within "the civilian context" without any meaningful nuclear weapon endeavors. Japan is one often-noted example, and latency is even sometimes called the "Japan Model" (Fitzpatrick 2014, 2016a). Latency is also called technical hedging. From a technical point of view, virtually any industrialized nation today has nuclear latency in one way or another. Yet, it is neither apt nor empirically correct to focus on only the material and technical capabilities to reach a theoretically rich and widely applicable definition of latency over a number of cases. Thus, it is 
arguably true that there is no settled definition of the term and no agreement among experts for an authoritative answer to the number of states having nuclear latency. Some suggest the figure is as high as sixty-nine (Barnaby 1992) while others put it around forty (Hymans 2006), thirty-four (Meyer 1984), and thirtyone (Fuhrmann and Tkach 2015) using different metrics and analysis. Yet, the nuclear latency question, as Sagan $(2010,80)$ underlined, is still understudied and poorly understood among experts, diplomats, scholars, and journalist.

Defining a nuclear state is still a futile exercise even though it is one of the most studied social science topics, let alone defining nuclear latency. However, it is purposeful to start with the nuclear weapon production process, which can be divided into two major steps. The first is the producing fissile material, which is enriched uranium or reprocessed plutonium. The second is actual bomb design, manufacturing, and testing. The former is known as the toughest and most time consuming part of a nuclear weapon program while the latter is relatively easier in the current environment than it was several decades ago (Zimmerman 1994). Any latent power should able to overcome the first step, which significantly shortens the time for reaching the nuclear weapon option. Thus, it is hard to separate the latency discussion from the proliferation discussion simply because the differences between civilian use of nuclear technology and nuclear weapons is rather a theoretical one. However, the proliferation of nuclear latency is distinct from weapons proliferation when these technologies have been used for indigenous civilian nuclear capacity and under strict international control. Furthermore, if a country would like to pursue a path towards nuclear weapons, it would choose opaque or secret proliferation, which will lower the chances of detection, instead of open and attention-grabbing civilian activities under Treaty on the Non-Proliferation of Nuclear Weapons (NPT) safeguards. According to Kemp's (2014) analysis, the probability of timely detection is almost zero, should a state opt for building centrifuge capacity indigenously. Given that centrifuge technology is old and technically reachable for almost any state, and that there are many other options as well if a state would like to produce nuclear weapon, transforming a civilian nuclear program into a weapon program would not be ideal. Therefore, a civilian nuclear program rarely leads to actual nuclear proliferation (Miller 2017). Yet, latency substantially increases a countries technological imperatives towards the bomb. ${ }^{1}$ Thus, the risk of proliferation from latency profoundly depends on political motivations, and therefore it is casespecific in nature.

Yet, many studies significantly focus on the technical aspects without looking at political intent to define latency and try to provide answers for exactly how many countries are latent powers. For instance, in his 1984 study, Meyer found that thirty-four states held latent capability to build nuclear weapons. Later, Meyer's study was updated by Richard Stoll (1996) to include developments up to 1992 . Based on this updated data (and methodology), ${ }^{2}$ Stoll argued that forty- 
eight countries had latent nuclear weapons capability in 1992. North-Korea, lacking the necessary nitric acid production capability, chemical engineers, and electronic/explosives specialists as measured by domestic automobile and radio/ television industries, was not among the listed latent nuclear powers at that time. Another well-known indicator set was developed by Jo and Garzke (2007) by droping three of Stoll's (and Meyer's) indicators (construction workforce, steel production, and previous mining activity) and adding necessary uranium deposits to the list. Even Jo and Gartzke's data set for 2001 showed that North Korea, which would go on to conduct its first nuclear weapon test in 2006, was not a latent nuclear power, lacking sufficient chemical engineers, nitric acid production capability, and explosives specialists. Even South Africa, which built six nuclear weapons in the 1980s, dismantled the weapons in the 1990s, but still maintained from 450 to $600 \mathrm{~kg}$ of highly-enriched uranium (HEU) under International Atomic Energy Agency (IAEA) safeguard inspections in 2002, was coded as a country that lacked the full capability to build nuclear weapons due to lack of sufficient chemical engineers and nitric acid production capacity (Sagan 2010, 88). Similarly, Colombia, Peru, Thailand, and Venezuela had the highest rank in Jo and Gartzke's eight-point composite indicator of latency even though none of these countries had constructed advanced nuclear facilities, nor the human capital or capacity to produce fissile materials (Fuhrmann and Tkach 2015). By pointing out these bizarre results, Sagan $(2010,81)$ suggests that these studies use "misleading measures of the key variables involved in nuclear technology, focusing on broad measures of industrial capability and nuclear research reactor experience and not on the specific fuel cycle technologies and facilities needed to make the fissile materials required for a nuclear weapon." Taking note of Sagan's suggestion, Furhmann and Tkach (2015) introduce a new dataset focusing on the development of enrichment and reprocessing facilities covering related data from 1939 to 2012. This new data sets indicates thirty-one countries as latent nuclear powers.

However, none of these studies can define which countries are a proliferation risk due to its latent capacity using different metrics and definitions and have produced different and often inconclusive results. Therefore, by focusing on the material and technical aspects of the story, the literature often falls into a trap of misperception and misinterpretation. Studying latency is important but difficult. It requires both technical expertise on the nuclear fuel cycle and advanced political science knowledge about a particular country. ${ }^{3}$

Overall, a working definition of latency for studying the Turkish case should consist of at least two aspects: (1) technical expertise including industrial scale enrichment and reprocessing facilities; (2) political conditions in which the latency option is wittingly presumed and even striven towards with several decision leading to that end. Thus, should the existing civilian nuclear facilities, all of which are under construction, have provided Turkey with the requiste 
technical expertise and capacities, and should Turkey's internal and political environment have been altered to a degree that pushes the country's leaders to make such a decision, then we could empirically argue that Turkey is a latent nuclear power. These technical and political conditions have to be analyzed to uncover the question of latency with regard to Turkey.

\section{The Turkish Case: How Latent Is It?}

Turkey has been listed as a latent power under the indicators produced by both Meyer/Stoll as well as Jo and Gartzke. It is also one of the forty-six members of the Nuclear Supplier Group; even though it is not a nuclear power state, Turkey's membership was requested due to its manufacturing capacity for materials of potential use in the nuclear industry. ${ }^{4}$ That is, Turkey has been recognized a (potential) latent nuclear power by some scholars and experts who mainly focus on the technical part of the latency metrics. Yet, Turkey does not possess the capability of constructing an industrial scale nuclear reactor to produce plutonium or the capability to produce enriched uranium. On this ground, Furhmann and Tkach (2015) do not count Turkey as a latent power in their latency list. From a purely technical point of view, Turkey has relatively advanced nuclear infrastructure as well as human capital due to its long interest in the nuclear technology (Acton and Bowen 2010, 444), yet it is far from being a latent nuclear power.

Turkey's interests in civilian nuclear technology dates back to the 1950s. It was among the first countries to sign an Atoms for Peace Agreement with the United States in June 1955. In 1956, Turkey founded the Turkish Atomic Energy (TAEK), under which it started to conduct very small nuclear fuel cycle research at the Cekmece Nuclear Research and Training Center, where one small research reactor, the TR-2 5MWt reactor, had been established. Over the years, Turkey tried and failed many times to build large industrial scale nuclear power reactors. However, due to a variety of political and financial reasons, especially because of the lack of political and financial stability, Turkey never moved beyond the research and development stages even though there were significant steps taken towards building nuclear power plants. During that time there was alleged close links between Pakistani and Turkish high-level authorities. That caused fear in some of the Western countries ove the illicit spread of nuclear technology. These alleged Pakistani connections were restricted and Turkey's initiatives were rebuffed (Kibaroglu 1997). Turkey still does not have a nuclear reactor or industrial scale enrichment or reprocessing capabilities, which is not a sufficient but a necessary part of nuclear latency in terms of technical capabilities (Varnum 2013). Nevertheless, given its contracted nuclear facilities and long running interest in nuclear technology, Turkey could have the necessary technical capacity 
in the near future. In this sense, rather than Turkey's current status, the risk of Turkey becoming a latent nuclear power in the future should be rigorously discussed.

\section{Turkey’s Latency Motivations}

Given its good relations with neighboring states, belief in alliances with the West and international regimes, desire for European Union (EU) membership, and preference for obtaining international prestige through diplomatic leadership, Turkey faced no serious proliferation pressures until 2010. However, Turkey's international and domestic politics have changed quickly, and the context of many of these constraints have transformed. Once predicted circumstances that could possibly push Turkey to consider the nuclear option have become realities in recent years (Fuerth 2004, 146). Yet, Turkey is still a good member of the nonproliferation regime by being part of almost every non-proliferation initiative and abiding by its non-proliferation commitments under these initiatives. Therefore, it is not easy to catalog all the motivations and predict their effects precisely. Yet, there are at least three types of motivations towards latency with regard to Turkish case, as seen in Table 1, which can be argued to be pushing Turkey's nuclear calculations.

\section{Security Related Motivations}

Regional Dynamics: Proliferation literature sees security related motivations as important drivers of nuclear weapon acquisition. When it comes to latency, as a technological hedging option, regional dynamics provide significant motivations for Turkey. Iran, and its long running nuclear program, in particular is highly salient for Turkey. There are number of studies that foresee Turkish nuclear proliferation in the case of Iran acquiring a nuclear weapon (Güney 2012). Although Iran's nuclear program has been temporarily stopped by the agreement between the P5+1 and Iran, known as The Joint Comprehensive Plan of Action (JCPOA), Iran's advancing nuclear infrastructure still remains a potential

Table 1. Turkey's Latency Motivations

\begin{tabular}{l|l|c}
\hline \hline Security Related Motivations & \multicolumn{1}{|c|}{ Domestic Motivations } & Technological Motivations \\
\hline - Regional Dynamics & - Energy related considerations & - Technological imperatives \\
- Weakening extended & - Domestic political dynamics & \\
deterrence and assurance: & & \\
NATO/U.S. and Western & & \\
Alliances & & \\
\hline
\end{tabular}

Source: Author 
trigger for a regional proliferation chain where other countries opt for similar capabilities (McFall 2017). Currently, Iran is the only country that is very close to being labeled as a latent nuclear power in the region. Saudi Arabia comes first among those who cannot afford the threat of a regional rival armed with (virtual) nuclear weapons. Turkey is also one of the aforementioned candidates for nuclear weapons within the nuclear community of experts. However, Turkey and Iran have managed to keep differences at the sub-strategic level by retaining deepening economic ties and opening state-to-state channels even though there are serious conflictual rivalry patterns, especially in Syria (Stein 2015). That has not changed in the current environment even though there are a number of geopolitical rivalries among them and even beyond. The North Atlantic Treaty Organization (NATO) alliance shapes Ankara's approach to security including the Iranian nuclear threat. Given the current diminishing level of trust between the United States and NATO, Turkey would be between a rock and a hard place in making the decision on nuclear latency, if not going for the full nuclear option. Given the low ebbs with the United States and other NATO allies, that possibility is indeed on the horizon.

Besides the Iran issue, Turkey also has a number of hot spots and increasing security risks and volatilities in its immediate periphery. External threats to Turkey, for a long time, have stemmed from non-state violent arms groups and terror networks. Ongoing PKK (Kurdistan Worker's Party) terrorism and a protoKurdish state which has emerged out of the chaos in neighboring countries are an existential threat to Turkey. Yet these types of threats do not require a nuclear deterrent as Turkey's advanced conventional capacities are potent enough. Indeed, since the end of the Cold War, Turkey has increased its development and procurement of advanced precision strike capabilities, many of which are homegrown. However, increasing threats on the menacing southern and eastern borders may force Turkey to take an alternative decision in the long-term. This is especially true when it comes to the increasing missile threat. Turkey first became truly concerned with the proliferation of ballistic missiles during the Iraq-Iran War in 1980s. Currently, all neighbors along the eastern and southern borders are known to have pursued militarization, acquisition of massive conventional weapons, proliferation of missiles, and even WMDs. Even though Israel is the only state that has not signed the NPT, Algeria, Sudan, and Israel have not signed the Biological Weapons Convention, and Egypt and Syria have thus far refused to sign the Chemical Weapons Convention. Iran is pushing ahead with its nuclear and missile programs. No state in the region is a formal member of the Missile Technology Control Regime, and many states in the region are known to have pursued nonconventional weapons in the past (Ulgen 2012). Moreover, not just states but also violent non-state actors armed with advanced weapons and missiles pose a great danger to Turkey. Turkey was under constant missile fire from ISIS for months, and is now under the threat of missiles from PKK/PYD 
in Syrian territory (PYD is the Syrian affiliate of the PKK). This pushes Turkey towards advancement and domestic capability building, which also increase its technical latency in terms of strategic delivery systems.

Russia may be the only country that threatens Turkey with nuclear retaliation. Russia has increased its nuclear and conventional capabilities with a sophisticated modernization program. Yet, Russian build-up historically and traditionally has not been aimed at Turkey. Furthermore, given Turkey's dependence on Russia for energy and trade, Turkey has strong incentives to maintain positive relations with Russia. However, since the annexation of Crimea, the balance of power has dramatically changed in the Black Sea. Changing security dynamics in the Black Sea area have become an important topic among Turkish security circles. With increasing tension between Russia and NATO, new Russian nuclear weapons, especially tactical and permanent deployments, will be more of a concern to Turkey in the near future. In the absence of the nuclear deterrence provided by NATO, Turkey would opt for nuclear hedging or for a minimal nuclear deterrence if it found itself on its own against Russia.

Weakening Extended Deterrence and Assurance: The United States and NATO have long formed the cornerstone of Turkish security to a degree that it is an integral part of the security establishment. Enhancement of that deterrence is required in order to reassure Turkey in the quickly deteriorating security environment underlined above. However, recently Turkey has begun to view the United States (and some other NATO allies) as untrustworthy and the credibility of the extended deterrence provided by the United States and NATO is diminishing.

The crisis in Syria has placed tremendous strain on U.S.-Turkey relations over the last several years. Given the uneasy situation at the strategic level and opposing views on priorities, Turkey believes U.S. resolve as it relates to the security of Turkey is at its lowest level since the Johnson Letter Incident in 1964. Especially, the U.S. decision to transfer heavy weapons to the Kurdish groups in Syria, who have clear ties to the PKK which is a designated terrorist organization by Turkey, created heavy strain. Moreover, the U.S. indifference to Fetullah Gulen, the mastermind behind the attempted coup on July 15, 2016 in Turkey, and refusal to take legal action against him and his activities have given rise to great anti-U.S. sentiment in Turkey. As result of these developments, the Turkish people perceive the United States to be the number one threat to Turkey instead of an ally (Hurriyet Daily News 2017).

Turkey's relations with other key NATO allies, such as Germany, has also drifted into the abyss since the coup-attempt and following purge in Turkey. The EU has been seen as a major proliferation constraint (Udum 2007), yet the EUTurkey relationship has been at an impasse for years with no sign of possible improvement. Turkey is also remarkably less enthusiastic about EU membership, 
which was one of the incentives to perform reforms, in the recent years amid high tensions between the country and the bloc.

From the deterrence perspective, the discussion on the removal of U.S. nuclear weapons at Incirlik Air Base (Fitzpatrick 2016b; Gotev and Schalit 2016; Lamothe 2016) will resonate in Ankara rather dauntingly. In fact, these tactical nuclear weapons in Turkey have little military value or purpose as there is no permanent nuclear capable U.S. fighter wings stationed at the air base and Turkey has no authority or capability to use them alone. There is an assumption that if the weapons were removed, Turkey's status in NATO would be negatively affected. ${ }^{5}$ The weapons are not only for deterrence but have a number of political implications and have come to symbolize the U.S. commitment to Turkey's defense (Ulgen 2012, 12). Therefore, their political significance is vital and Iran's nuclear program complicates the issue. A nuclear Iran could spark an arms race in the Middle East and bring about a "proliferation cascade," which may cause Turkey to reconsider its nuclear options-especially if the United States pulls its nuclear weapons from Incirlik (Bell and Loehrke 2009). In the absence of nuclear deterrence, a nuclear capable Iran significantly affects Turkish proliferation policy and Turkey would probably take steps in pursuing more robust scientific expertise and nuclear infrastructure for nuclear hedging to balance Iran.

Extended deterrence provided by the United States, NATO, and the EU as an institution still remain the most important proliferation constraints for Turkey. Disenchantment with the EU, eroding U.S. credibility, as well as the increasingly louder discussions on whether U.S. nuclear weapons should continue to be stationed in Turkey and calls to remove them are therefore possible proliferation pressures for military strategic planners as well as politicians. And these proliferation pressures may revitalize Turkish interest in nuclear latency.

\section{Domestic Motivations}

Energy Related Motivations: The most important drivers of nuclear technology in the world and Turkey are energy related considerations. Turkey has the highest rate of growing energy demand among Organisation for Economic Co-operation and Development (OECD) countries over the last fifteen years while it has long been facing limited supplier options and highly volatile fossil fuel prices with a high import dependency rate. The country imports 98 percent of its natural gas and 93 percent of its oil, which costs well over $\$ 60$ billion annually. Given the increasing cost of energy, there are increasing concerns about Turkey's energy insecurity as the country grows. To reduce its energy import dependency, nuclear energy is one of the most stable and cost-effective alternatives for the country. Turkey pursues nuclear energy programs first and foremost because of a set of energy-related motivations.

For Turkey, building nuclear power plants is economically rational in terms of both decreasing heavy reliance on fossil fuels and heavy reliance on a 
Table 2. Planned and Proposed Nuclear Power Reactors

\begin{tabular}{c|c|c|c|c}
\hline \hline Site & Type & MWe Gross & Start Construction & Start Operations \\
\hline Akkuyu 1 & VVER-1200 & 1200 & 2018 & 2023 \\
\hline Akkuyu 2 & VVER-1200 & 1200 & 2019 & 2023 \\
\hline Akkuyu 3 & VVER-1200 & 1200 & 2020 & 2024 \\
\hline Akkuyu 4 & VVER-1200 & 1200 & 2021 & 2025 \\
\hline Sinop 1-4 & Atmea1 & $4 \times 1120$ & - & - \\
\hline Igneada 1-2 & AP1000x2 & $2 \times 1250$ & - & - \\
\hline Igneada 3-4 & CAP1400x2 & $2 \times 1400$ & - & - \\
\hline
\end{tabular}

Source: World Nuclear Association (2018)

few countries (Russia and Iran) for its substantial energy import. Turkey will probably produce at least around 10 to 16 percent of its electricity needs from nuclear power in the near future. To this end, Turkey has engaged in several nuclear power plant projects since the early 1960s. Recent economic and political changes have resulted in a so-called nuclear renaissance in Turkey since 2009, when decisive steps were taken to build nuclear power plants. For the first nuclear power plant project, Turkey has signed an agreement with Russia that states a subsidiary of Russias state-owned atomic power company Rosatom would build, own, and operate a nuclear power plant at the Akkuyu site. ${ }^{6}$ Compared to other suppliers, Russia offered a more generous proposal (Ulgen and Perkovich 2015). As a matter of fact, the agreement appears to be an economically advantageous deal for Turkey considering the prices and profits included (Ulgen et al. 2016). This power plant (consisting of four VVER-1200 reactors with a total capacity $4.800 \mathrm{MW}$ ) is expected to be partly operational in 2023 . The second power plant has been contracted to a Franco-Japanese consortium, yet the project's start and finalization dates are not certain at the moment. A third power plant is also in the planning stages and is expected to be contracted to a Chinese company.

Turkey is part of a growing movement among developing and developed states that are pursuing nuclear energy as a way to decrease carbon emissions while also decreasing reliance on unstable foreign energy suppliers. In the Middle East alone, thirteen countries without the same economical rationality as Turkey been pursuing a dormant nuclear agenda. Two prominent nuclear experts underlined that Turkey has valid economic arguments for developing the capacity to produce nuclear energy since the country has a huge current-account deficit due to the high portion of energy import and its electricity demand continues to grow at 5-6 percent per year (Ulgen and Perkovich 2015).

Therefore, nuclear power has to be seen as an energy issue, and even as an energy security issue, rather than solely as a security issue let alone a problem of 
regime survival in the Turkish context (Udum 2010).

Domestic Political Dynamics: The debate over nuclear energy in Turkey is robust and inexorably entwined with domestic politics. Different parts of society take part in the nuclear discussion for different reasons. Even though there is no scientific study on public opinion regarding nuclear energy, according to Udum (ibid.), a well-known Turkish expert on the nuclear issue, constituencies that support nuclear power in Turkey comprise very different parts of Turkish society including political parties, the business sector, and civil society groups consisting of unions and academics. However, the most important fact is that very few pundits loudly express support for a nuclear weapon capacity as a hedging strategy within security discourse. Yet, it is difficult to assess whether or not there is genuine support for nuclear latency among the Turkish public in general. One important point is also the fact that the media, both private and public, do not traditionally have a significant role in national security decisions. Civilian nuclear energy, however, is generally characterized as symbol of modernity and economic progress. Nuclear energy for many Turkish politicians, elites, and intellectuals is a defiant quest for modernity.

Should Turkey decide for the nuclear latency option, the military's support is necessary but not sufficient in the current environment. Another body who's support would be required is the National Security Council, which has been under civilian control since 2008. Turkey also has substantial civilian entities with nuclear expertise many of which are directly controlled by the office of prime minister. However, these civilian bodies are now under full-presidential oversight since the office of prime minister has been abolished due to the recent constitutional changes. The Science and Technology Supreme Board, National Nuclear Technology Development Program, and Turkish Atomic Energy are some of these state entities. A nuclear decision would require active involvement of these bodies, and in Turkey these bodies are wholly civilian entities in terms of both human resources and budgetary oversight. In this sense, a military decision which could lead to an opaque proliferation would not be easy in the Turkish context. The Turkish military could play a decisive role in the past. Yet, in the current climate of Turkish politics, the president is the most probable candidate to make the decision to move towards nuclearization. That does not mean that he could make such a decision alone. Yet, compared to the past, the president has more power in making such a decision. Legally speaking, a nuclear weapons program would require the acquiescence of the Turkish General Assembly (TBMM) and the president's consent, as well as cooperation from at least some of these civilian entities. Therefore, a latency decision has to be made through a consensual process; not all players are equally influential, yet none can individually control the outcome.

From a theoretical point of view, Solingen's domestic political survival model 
argues that leaders of internationalizing domestic coalitions have incentives to avoid the political, economic, reputational, and opportunity costs of acquiring nuclear weapons, while inward-oriented regimes are unsurprisingly more likely to pursue nuclear weapons not only from a political economy standpoint but also because such regimes typically embrace the kind of oppositional nationalism that casts nuclear weapons acquisition in a positive light (Solingen 2009). However, it is also true that more restrictive rule and nuclear weapons aspirations can undermine rather than support the development of civilian nuclear power as is often presumed in the literature (Jewell and Ates 2015). When it comes to Turkey, neither the current government under the AKP (Justice and Development Party) nor Turkey's military favor inward-oriented political survival models. They have embraced economic and political liberalization. They face strong material disincentives to pursue nuclear weapons because their prosperity depends on Turkey's continued good-citizen status. Turkey is therefore likely to continue to pursue prestige from multilateral interactions, constraining it from pursuing nuclear weapons.

\section{Technological Motivations}

Technological Imperatives: In the literature, it is often acknowledged that the decision to acquire nuclear latency is driven by a combination of security motivations, domestic politics, and elements of technological determinism (Mehta and Whitlark 2016). Technological imperatives are a natural byproduct of technological capacity; that is, once a country has the ability to select the latency option it would choose to do so, and once a country is fully latent it would go for actual nuclear proliferation. For example, existing research on nuclear weapons proliferation has shown that a country's level of economic or industrial development may serve as an important driver for acquiring nuclear weapons (Jo and Gartzke 2007). When it comes to Turkey, due to its current level of technical capability, latency is not an easily reachable option for the time being, let alone actual proliferation. As Mark Hibbs (2015) states: "If Turkey were to aim for a nuclear-weapons capability, it would have quite a long road to travel. I say that because there's nothing on record-not in the open literature, not on file at the IAEA Department of Safeguards, and apparently not in current U.S. government intelligence dossiers - that documents any Turkish undeclared nuclear activities." Therefore, the actual question concerning Turkey is how latent it could be rather than how latent is it.

\section{Turkey and Technical Nuclear Proliferation towards Latency: How Latent Could It Be?}

A nuclear power program can be a stepping stone to or a cover-up for a nuclear 
weapons program. Thus, any new nuclear energy program raises potential proliferation questions (Udum 2010). The Turkish case is no different. Yet, the most important point here is the fact that, if the all the construction projects are finalized as outlined, Turkey will be the first in the world to rely on foreign vendors to own and operate nuclear power plants. ${ }^{7}$ Departing from the fact that the nuclear fuel-cycle and nuclear waste management have not been clearly addressed in the agreements made between Turkey and the foreign vendors, some argue that Turkey has (secret) intentions to maintain the option to run the reactors with its own low enriched uranium (Rühle 2015), which is not illegitimate under the NPT and technically would open Turkey's path to producing nuclear fissile materials. A 2014 report, based on estimates by the German intelligence service, claimed that Turkey was adopting the Iranian model-a civilian nuclear program on the surface with a military program underneath (ibid.). Turkey has not ruled out the option of indigenous uranium enrichment capacity, which is a given right under the NPT. However, Turkey is not Iran, nor North Korea, and should not be treated as such. Turkey is a wellbehaved member of the NPT regime with a top-ranked non-proliferation record due to its long-standing compliance with NPT requirements as recorded by the main watchdog IAEA (Ulgen 2012). Indeed, then Turkish Energy Minister Taner Ylldiz ruled out the claims that Turkey secretly opted for uranium enrichment (Hürriyet Daily News 2014). Later, Turkey issued a joint statement with eleven other countries to eliminate HEU and its replacement (Haaretz 2014). These are indicators that Ankara has been actively seeking to maintain its clean nonproliferation record. Moreover, since 2012, Turkey has received the IAEA's so-called "broader conclusion" designation, reiterating its clean nonproliferation record.

Indeed, when we look at the Turkish regulations on nuclear waste management and nuclear fuel procurement, these issues may be left for further negotiations due to attached financial costs, yet it is explicitly stated that these issues are the responsibility of the foreign operating companies. The agreement made with Rosatom provides for further cooperation between Russia and Turkey in other areas of the nuclear fuel cycle including the treatment of used nuclear fuel and radioactive waste, decommissioning, and the possible construction of a Turkish nuclear fuel fabrication plant. Yet, the finalized agreement and Russian code of conduct on the fuel cycle and nuclear power plant establishment clearly states that the Russian side is the owner of the nuclear fuel while Turkey has almost no authority in the usage of the spent fuel (Pekar 2014, 2). For the projected power plant to be located at Sinop, Turkey has searched for cooperation in other areas of the nuclear fuel cycle including the treatment of used nuclear fuel and radioactive waste, which also cast doubts about Turkey's long-term intentions. For this project, the procedure for the nuclear fuel and waste management is not clear, yet it is highly anticipated that the French side 
would bear the responsibility for both fuel and waste management since it is the only party with that particular capability. This is important because, under the Build, Operate, and Own (BOO) financing and operating model, "if Turkey decided to use these reactors to proliferate, it would first have to kick out the foreign operator and then separate the foreign-owned spent fuel stored on site, before fashioning a crude implosion bomb, which is not feasible" (Stein 2015). Therefore, it is clear that Turkey will not be able to have any enrichment activities in the short- and medium-term at its projected nuclear power plants. Moreover, the biggest deficiency in nuclear development is in human resources as the country still lacks indigenous expertise on the issue of nuclear energy. The ongoing construction and cooperation agreements will boost Turkish human resources in nuclear expertise, yet Turkey may also face difficulties developing a singular and focused nuclear energy industry, largely because financing concerns have prompted the government to make disparate decisions about reactors. Thus, Turkish technicians trained as part of the program to operate Akkuyu will not have transferable skills for the Sinop plant and vice versa. (Stein 2016). Turkey also has a modest level of uranium deposits. However, the raw material is not a problem for any amount of nuclear activity in Turkey. Overall, Turkey will not be able to reach genuine nuclear latency due to the nature of the ongoing nuclear power plant projects even if it has several industrial scale civilian nuclear reactors.

Why, then, has Turkey deliberately left open an indigenous enrichment option? Here, it should be noted that Turkey profoundly emphasizes the right to enrichment under the NPT. The Turkish policy regarding Iran sanctions is a microcosm for Turkish nuclear diplomacy. Turkey has accepted and implemented the multilateral sanction regime of the United Nations Security Council (UNSC), while has refusing to obey by the American and European sanctions not just because they were harmful to its economy but also because the West's demand that Iran halt enrichment as a clear violation of Iran's right under the NPT to pursue nuclear activities (Ulgen 2012, 7). Under Article IV of the NPT, every signatory has the right to pursue peaceful nuclear activities and nuclear supplier countries are obligated to facilitate the exchange of nuclear technology and materials. In recent years, the Turkish interpretation of Article IV has been a source of friction between Turkey and some of its Western allies, especially when it comes to international efforts to limit nuclear aspirant countries from accessing enrichment and reprocessing technologies. Turkish official views of these efforts as a threat to Turkey's own nuclear ambitions and have challenged proposals designed to make it harder for a state to access nuclear technologies (ibid., 14). Turkey's nuclear diplomacy is influenced strongly by the fact that it is a non-nuclear weapons state seeking to develop an indigenous nuclear energy program. Ankara has positioned itself as a champion of nonproliferation, while maintaining a strict interpretation of Article IV of the NPT (Ulgen 2011, 145). 


\section{Conclusion}

From a proliferation standpoint, enrichment technologies for reactors can be applied to nuclear weapon development. That is, if a country has the ability to enrich uranium to reactor level (low-level enrichment) then that country can level up its uranium stockpile to weapons grade (high-level enrichment) within a relatively small amount of time, which gives a country latency from a technical point of view. The key point here is whether the country that has reprocessing capabilities obeys the rules of the international nonproliferation regime. Departing from this fact, Turkey has not announced any plans to pursue enrichment or reprocessing; on the contrary, by the nature of its existing operation and finance model for its projected power plants and by the nature of its commitment to the nonproliferation regime, it has shown good practices. Turkey has reiterated that uranium enrichment is a future long-term option should Turkey build a lot of nuclear power reactors, but is not currently being pursued (Hibbs 2015). Moreover, nuclear fuel has always been available on the international market for small and medium sized nuclear programs. Indigenous production is not economical unless there is intent for industrial scale enrichment (Fitzpatrick 2014). In this sense, there are at least two important points that can be drawn from the assessments given in this article: (1) Turkey will not have industrial-scale enrichment or reprocessing capabilities in the short- or mediumterm; and (2) as long as Turkey remains a well-behaved member of the nonproliferation community and takes care to protect its clear record, suspicion of "bad intentions" is ill-placed. Such changes are only possible if Turkey's domestic political and external security environment change dramatically.

However, Turkey's recent interest and efforts to develop nuclear energy production along with its indigenous capabilities are sometimes characterized as the first step towards nuclear latency (Stein 2015). Current Turkish civilian energy plans are completely related to the economic needs of the country. Turkey does not presently have the necessary infrastructure to produce fissile materials for a nuclear weapon, nor it does possess the relevant infrastructure to mine uranium, enrich uranium, or reprocess spent fuel (Ulgen 2012, 21). It will not be capable of these tasks in the near and medium future. Almost all of its indigenous capabilities, such as short- and medium-range missiles, missile defense, small space program, are driven by its security needs. Therefore, all things considered, Turkey's latency in the technical area will increase, yet that increase cannot be thought of as potent enough to be considered a latent nuclear weapons program in the short-term without a serious change in international and domestic politics.

An economically rational, politically inclusive, and technically transparent peaceful pursuit of nuclear energy under the eye of a strong and verifiable international watchdog agency and the international non-proliferation community is not a threat. Although a latent nuclear capability may arise through 
a domestic nuclear energy program, Turkey is unlikely to take advantage of that under the current internal and external political environment.

\section{Notes}

1. Accroding to Meyer (1984, 9-10), possible dependent variables in the proliferation field are: (1) the development of a latent nuclear weapons capacity, whether this is intentional or as an unintented byproduct of other choices; (2) the conscious "capability decision" to generate a certain level of nuclear weapons breakout capacity; and (3) the actual acquisition of a functional arsenal.

2. While Meyer measured indigenous uranium sources, Stoll assumed that all states had access to nuclear materials, arguing that they were now freely available on the global market. See Sagan $(2010,85)$.

3. For a good example, see Mehta and Whitlark (2016).

4. Being a member of the Nuclear Supplier Group does not necessarily imply a latency metric itself. Nevertheless, it points to a certain accrual of a standard set of nuclear technology capabilities.

5. For a counter argument, see Kibaroglu (2011).

6. As tension rose after a Russian jet was downed by Turkey, the project was reportedly terminated. Yet, a broad rapprochement has been achieved, and construction has officially started. However, this brief case shows that Turkey's nuclear future is politically unstable given the turbulent relations of the country.

7. This is a direct result of the "Build, Operate, and Own" financing model that Turkey increasingly relies on for many other big infrastructure projects as well. This financing model requires that the nuclear vendor provide financing for the construction of the reactor and operates it for the life of the power plant in return for the Turkish stateowned electricity utility guaranteeing a purchase price for an agreed amount of electricity produced at the plant. If it goes well, it would be replicated in other countries too.

\section{References}

Acton, James, and Wyn Q. Bowen. 2010. "Civilian Nuclear Power in the Middle East: The Technical Requirements." In Nuclear Power's Global Expansion: Weighing Its Costs and Risks, ed. Henry Sokolski, 423-475. Carlisle: Strategic Studies Institute.

Barnaby, Frank, ed. 1992. Plutonium and Security: The Military Aspects of the Plutonium Economy. Basingstoke: Palgrave MacMillan.

Bell, Alexandra, and Benjamin Loehrke. 2009. "The Status of U.S. Nuclear Weapons in Turkey." Bulletin of the Atomic Scientists, November 23. http://thebulletin.org/statusus-nuclear-weapons-turkey (accessed September 4, 2018).

Bluth, Christoph, Matthew Kroenig, Rensselaer Lee, William C. Sailor, and Matthew Fuhrmann. 2010. "Civilian Nuclear Cooperation and the Proliferation of Nuclear Weapons." International Security 35 (1): 184-200.

Bunn, Matthew. 2001. "Civilian Nuclear Energy and Nuclear Weapons Programs: 
The Record." http://core.csu.edu.cn/NR/rdonlyres/Nuclear-Engineering/22812JSpring2004/DA39D9C3-72E5-426E-840C-712594207E23/0/prolif_history.pdf (accessed September 4, 2018).

Fitzpatrick, Mark. 2014. "Nuclear Latency with an Attitude." IISS, October 7. https:// www.iiss.org/en/politics\%20and\%20strategy/blogsections/2014-d2de/october-931b/ nuclear-latency-c8a6 (accessed September 4, 2018).

Fitzpatrick, Mark. 2016a. Asia's Latent Nuclear Powers: Japan, South Korea and Taiwan. London: International Institute for Strategic Studies.

Fitzpatrick, Mark. 2016b. "Removing Nuclear Weapons from Turkey." Survival 58 (5): 5358.

Fuerth, Leon. 2004. “Turkey: Nuclear Choices amongst Dangerous Neighbors.” In The Nuclear Tipping Point: Why States Reconsider Their Nuclear Choices, eds. Kurt M. Campbell, Robert J. Einhorn, and Mitchell B. Reiss, 145-174. Washington, D.C: Brookings Institution Press.

Fuhrmann, Matthew, and Benjamin Tkach. 2015. "Almost Nuclear: Introducing the Nuclear Latency Dataset." Conflict Management and Peace Science 32 (4): 443-461.

Gotev, Georgi, and Joel Schalit. 2016. "US Moves Nuclear Weapons from Turkey to Romania." Euractiv, August 18. http://www.euractiv.com/section/global-europe/news/ us-moves-nuclear-weapons-from-turkey-to-romania/ (accessed September 4, 2018).

Güney, Nurşin Ateşoğlu. 2012. "Turkish Nuclear Security after Iranian Nuclearization.” Contemporary Security Policy 33 (3): 512-529.

Haaretz. 2014. “Turkey Eliminates Highly Enriched Uranium in Its Territory." March 24. http://www.haaretz.com/world-news/1.581753 (accessed September 4, 2018).

Hibbs, Mark. 2015. “The IAEA's Conclusion About Turkey." Carnegie Endowment for International Peace, April 16. http://carnegieendowment.org/2015/04/16/iaea-sconclusion-about-turkey-pub-59802 (accessed September 4, 2018).

Hürriyet Daily News. 2014. “Turkish Energy Minister Denies Uranium Enrichment Intention.” January 9. http://www.hurriyetdailynews.com/turkish-energy-ministerdenies-uranium-enrichment-intention-60787 (accessed September 4, 2018).

Hurriyet Daily News. 2017. "72 Percent of Turkish Citizens See US as Security Threat," August 2. http://www.hurriyetdailynews.com/72-percent-of-turkish-citizens-seeus-as-security-threat-.aspx?pageID $=238 \& n I D=116272 \&$ NewsCatID $=358$ (accessed September 4, 2018).

Hymans, Jacques E. C. 2006. "Theories of Nuclear Proliferation:The State of the Field." The Nonproliferation Review 13 (3): 455-465.

Jewell, Jessica, and Seyithan Ahmet Ates. 2015. "Introducing Nuclear Power in Turkey: A Historic State Strategy and Future Prospects." Energy Research \& Social Science 10 (November): 273-282.

Jo, Dong-Joon, and Erik Gartzke. 2007. "Determinants of Nuclear Weapons Proliferation.” Journal of Conflict Resolution 51 (1):167-194.

Kemp, R. Scott. 2014. “The Nonproliferation Emperor Has No Clothes: The Gas Centrifuge, Supply-Side Controls, and the Future of Nuclear Proliferation." International Security 38 (4): 39-78.

Kibaroglu, Mustafa. 1997. “Turkey’s Quest for Peaceful Nuclear Power." The Nonproliferation Review 4 (3): 33-44.

Kibaroglu, Mustafa. 2011. “Turkey, NATO and Nuclear Sharing: Prospects after NATO's 
Lisbon Summit." Nuclear Policy Paper No. 5, British American Security Information Council, April. http://www.basicint.org/sites/default/files/Nuclear_Policy_Paper_ No5.pdf (accessed September 4, 2018).

Lamothe, Dan. 2016. “The U.S. Stores Nuclear Weapons in Turkey. Is That Such a Good Idea?" Washington Post, July 19. https://www.washingtonpost.com/news/checkpoint/ $\mathrm{wp} / 2016 / 07 / 19 /$ an-old-nuclear-weapons-deal-raises-new-questions-about-u-sbombs-in-turkey/ (accessed September 4, 2018).

Mazarr, Michael J. 1997. Nuclear Weapons in a Transformed World: The Challenge of Virtual Nuclear Arsenals. New York: Palgrave Macmillan.

McFall, Schawn. 2017. “The Perception Gap Over Nuclear Proliferation in the Middle East." E-International Relations, July 13. http://www.e-ir.info/2017/07/13/the-perceptiongap-over-nuclear-proliferation-in-the-middle-east/ (accessed September 4, 2018).

Mehta, Rupal N., and Rachel Elizabeth Whitlark. 2016. "Unpacking the Iranian Nuclear Deal: Nuclear Latency and U.S. Foreign Policy." The Washington Quarterly 39 (4): 4561.

Meyer, Stephen M. 1984. The Dynamics of Nuclear Proliferation. Chicago: University of Chicago Press.

Miller, Nicholas L. 2017. "Why Nuclear Energy Programs Rarely Lead to Proliferation." International Security 42 (2): 40-77.

Narang, Vipin. 2017. "Strategies of Nuclear Proliferation: How States Pursue the Bomb." International Security 41 (3): 110-150.

Pekar, Cigdem Bilezikci. 2014. “Turkey's Nuclear Power Plans and Nuclear Fuel Cycle Options." EDAM Discussion Paper Series No. 2014/4, http://edam.org.tr/wp-content/ uploads/2014/05/Turkeys-Nuclear-Power-Plans-and-Nuclear-Fuel-Cycle-Options.pdf (accessed September 4, 2018).

Pilat, Joseph F. 1997. "Virtual Nuclear Weapons." United States Institute for Peace.

Pilat, Joseph F. 2015. "Exploring Nuclear Latency." Wilson Center, February 25. https:// www.wilsoncenter.org/publication/exploring-nuclear-latency (accessed September 4, 2018).

Rühle, Hans. 2015. “Is Turkey Secretly Working on Nuclear Weapons?” The National Interest, September 22. http://nationalinterest.org/feature/turkey-secretly-workingnuclear-weapons-13898 (accessed September 4, 2018).

Sagan, D. 2010. "Nuclear Latency and Nuclear Proliferation." In Forecasting Nuclear Proliferation in the 21st Century, eds. William C. Potter and Gaukhar Mukhatzhanova, 80-101. Stanford: Stanford University Press .

Solingen, Etel. 2009. Nuclear Logics: Contrasting Paths in East Asia and the Middle East. Princeton: Princeton University Press.

Stoll, J. Richard. 1996. "World Production of Latent Nuclear Capacity." http://es.rice.edu/ projects/Poli378/Nuclear/Proliferation/proliferation.html (accessed October 30, 2018).

Stein, Aaron. 2015. "Is Turkey Going Nuclear?" The American Interest, August 25. https:// www.the-american-interest.com/2015/08/25/is-turkey-going-nuclear/ (accessed September 4, 2018).

Stein, Aaron. 2016. “Turkey Nuclear Program: Challenges and Opportunities.” Atlantic Council, Issue Brief, December. http://umfp.org/wp-content/uploads/2016/12/ Turkey_Nuclear_Program_12-21-16.pdf (accessed September 4, 2018). 
Udum, Şebnem. 2007. “Turkey's Non-Nuclear Weapon Status: A Theoretical Assessment.” ISYP Journal on Science and World Affairs 3 (2): 57-65.

Udum, Şebnem. 2010. "Turkey's Nuclear Comeback: An Energy Renaissance in an Evolving Regional Security Context.” The Nonproliferation Review 17 (2): 365-377.

Ulgen, Sinan. 2011. “The Security Dimension of Turkey's Nuclear Program: Nuclear Diplomacy and Non Proliferation Policies." In The Turkish Model for Transition to Nuclear Power, ed. Sinan Ulgen, 142-183. Istanbul: EDAM.

Ulgen, Sinan. 2012. Turkey and the Bomb. Washington D.C.: Carnegie Endowment for International Peace.

Ulgen, Sinan, and George Perkovich. 2015. "Why Turkey Won't Go Nuclear." Carnegie Endowment for International Peace, April 10. http://carnegieendowment.org/2015/ 04/10/why-turkey-won-t-go-nuclear-pub-59756 (accessed September 4, 2018).

Ulgen, Sinan, Izak Atıyas, Mithat Celikpala, Pelin Demirci, and Ergun Doruk. 2016. "Managing the Risk of Nuclear Energy: Turkish Case." EDAM, Centre for Economics and Foreign Policy Studies. http://edam.org.tr/en/AnaKonu/managing-the-risks-ofnuclear-energy -the-turkish-case (accessed September 4, 2018).

Varnum, Jessica C. 2010. "Turkey in Transition: Towars or Away from Nuclear Weapons." In Forecasting Nuclear Proliferation in the 21st Century, eds. William C. Potter and Gaukhar Mukhatzhanova, 229-254. Stanford: Stanford University Press.

Varnum, Jessica C. 2013. "Closing the Nuclear Trapdoor in the U.S.-Turkey Model Partnership.” Brookings, June 17. https://www.brookings.edu/research/closing-thenuclear-trapdoor-in-the-u-s-turkey-model-partnership-opportunities-for-civilnuclear-cooperation/ (accessed Septmeber 4, 2018).

World Nuclear Association. 2018. "Nuclear Power in Turkey." Accessed October 30, 2018. http://www.world-nuclear.org/information-library/country-profiles/countries-t-z/ turkey.aspx.

Yim, Man-Sung, and Jun Li. 2013. "Examining Relationship between Nuclear Proliferation and Civilian Nuclear Power Development." Progress in Nuclear Energy 66 (July): 108114.

Zimmerman, Peter D. 1994. "Proliferation: Bronze Medal Technology Is Enough.” Orbis 38 (1): 67-82.

Hakan Mehmetcik is an Assistant Professor in the Department of International Relations at Marmara University, Turkey. He has two master degrees in Economics and Eurasian Studies from Dalarna and Uppsala Universities in Sweden. He finished his Ph.D. in 2017 in International Relations from Yildiz Technical University in Turkey and his research interests lie in the areas of international political economy, regionalism, globalization, and broader security studies with a special interest on deterrence and nuclear proliferation. He has several major publications on middle powers, rising powers, and Turkish foreign policy. Recent articles have appeared in International Politics and Third World Quarterly. 
